\title{
A Research on Quality Assurance in Arts Classroom Teaching in Higher Education in China
}

\author{
Ping Huang, Jing Chen, Wenjing Zheng \\ Faculty of Education, Sichuan Normal University, Chengdu, China \\ Email: huangpingpingp@yahoo.com.cn, cjbelinda@126.com,tk.jing@foxmail.com
}

Received 2013

\begin{abstract}
Classroom teaching is one of the most important aspects and links to assure quality in higher education. Although there have been some theoretical discussions and research by Chinese scholars about how to enhance the quality of classroom teaching in higher education, the experimental research of quality assurance in teaching is rarely seen. Based on an exploration of the teaching-learning methods of the presentation model, this article will provide evidence that interactive teaching styles, especially Presentation Teaching Methods, are very efficient in improving the quality of arts classroom teaching in higher education. It will analyze the quality and quantity of the empirical knowledge, which includes consciously challenging authority, academic research competencies of critical reading, critical writing and some practical abilities in finding, analyzing, solving problems and team work. Finally, it will provide some suggestions for quality assurance in classroom teaching in higher education.
\end{abstract}

Keywords: Quality Assurance in Classroom Teaching; Analysis of Empirical Knowledge; Developing the Students' Competencies; Interactive Teaching Styles

\section{Introduction}

Ever since the Ministry of Education of China implemented the new policy of rapidly expanding the enrollment of new studentsin higher education in 1999, there is no doubt that the quality of classroom teaching has declined due to a shortage of lecturers, professors and teaching facilities including computers, classrooms and libraries. The issue of gradually increasing difficulties for graduates in finding jobs has appeared and become very grave. Also, Qian Xuesheng, the well known scientist posed this question eight times to Wen Jiabao, the Prime Minister of China: "Why do universities in China not cultivate excellence at all times?”The “Questioning of QianXuesheng” pushes the quality assurance in higher education to the front of the debate (The Ministry of Education Press Office\&China National Institute for Educational Research, 2010). Moreover, in theEssentials of National Middle-Long-term EducationalReform and Development Plan(2010-2020),the Chinese government pointed out: “ improving quality is the core task of education reform and development”(Ministry of Education of China,2010).Classroom teaching is one of the key aspects and links to assure quality of education. Therefore, how to improve the effectiveness of classroom teaching to guarantee higher educational quality becomes more necessary and important.

There are manydiscussions about effective teaching in higher education by some Chinese scholars. However, most of them focused on the general principles or theoretical discussion about improving teaching efficiency. It is very rare to see research about quality assurance using empirical research of classroom teaching. This research project studied The Australian Higher Education Quality Assurance Framework(Department of Education, Training and Youth Affair, Australia, 2000) and found that it is one of the vital criteriato evaluate higher education qualityand whether the graduates could find satisfying jobs. Quality assurance in classroom teaching emphasizes cultivating the capabilities of learning and solving problems in order to match the social demands to the students' talents. It has been found that during the process of quality assurance, the presentation teaching method is implemented extensively in higher education in Australia. For this reason, the research group conducted a survey in several universities in Guangzhou and at some Arts Faculties in Sichuan Normal University, followed by constructive experimental research in Arts Classes in Higher Education, where the teaching method was changed from the instructional model to the interactive model. This included some academic research competencies of consciously challenging authority, critical reading and thinking, as well as the competencies of dealing with social practical problems, such asfinding,analyzing and solving practical problems.

\section{The Current Situation in Arts Classroom Teaching in Higher Education}

\section{Literary Review}

The literature review indicated that the teaching ideas and styles in universities still focuses on transmitting knowledge rather than developing students' abilities although China has changed elite education into mass education. The predominant educational philosophy is still teacher - centred in higher education in China. Most lecturers and professors believe that delivering subject knowledge systematically is more important than developing students' abilities. Therefore, there is little chance for students to improve their abilities, particularly those of finding, analyzing, problem solving and creativity (Ma \& Liu, 2008; Li \& Li, 2011). The lecturers are more concerned 
with how to transform knowledge and cover all the knowledge points. Homework and tests are focused on assessing the students' understanding and memory of the theories taught in the classroom. Methods of assessing the efficiency of learning usually consist of various types of closed-book exams. It is very common to see lecturers talk continuously for almost the whole class while students do their best to take notes as much as they can in order to meet the various test requirements. This is the same process as primary and middle schools(Song, 2011; Yi, 2010; Zhao \&Guo J 2010).However, In 2007, the National Bureau of Statistics of China issued a sampling survey, in which the sampling fraction was $0.900 \%$ and the sample surveyed waspeople above 6 years of age.This survey indicated that only about $6.5 \%$ of Chinese people received higher education(Huang, 2009). It indicated that China does not have too many graduates. However,numerous companies have difficulty in recruiting graduateswho have the desired abilities: finding,analyzingand problem solving, and the ability to work cooperatively. This condition indicates a truth, which isthat the instructional model of imparting knowledge does not satisfactorily match the human resources market demands.

\section{SamplingSurvey}

A sampling survey of teaching styles in higher education was conducted, which involved367Arts students in Zhongsan University, 63Arts students in Guangzhou University, 110 Arts students in Guangzhou Traditional Chinese Medical University and 321Arts students in Sichuan Normal university. These 861 students experienceddifferent learning styles. Table 1shows $71.8 \%$ of subjects are still taught by the dissemination of large amounts of theories through transmission teaching styleswhich neglects the cultivation of students' abilities to apply those theories (Huang, 2013). This leads to most students simply learning and memorizing basic theories. The skills of finding, analyzing and problem solving are not developed effectively in many universities(Ma \&Liu, 2008).

A sampling survey of teaching methods that undergraduates would like to experience was conducted using the same respondents. Creating a responsive atmosphere, guiding students to join in and share knowledge and information was added as option "E". The survey showed that $77 \%$ of students chose "E”. If added to option "C", there are $91 \%$ of students willing to experience interactive teaching styles rather than the usual transmission teaching style (Pie chart 1). No students chose "D”. These two sampling surveys display that on one hand, transmission-teaching styles are applied in most Arts classes
(Table 1), and on the other hand, undergraduates wish to experience interactive teaching styles (Huang, 2013)

\section{Educational Essence, Quality and Goal}

Jia Fuming, an educationalist from Taiwan, pointed out that the essence of education is the answer to why we teach(Jia, 2007). In theEssentials of National Middle-Long-term EducationalReform and Development Plan (2010-2020), it stated: "education should be people-centered, this is the fundamental requirement for educators, ... it is the fundamental standard for judging the quality of education to facilitate people's comprehensive development and adapt tothe demands of society"(Ministry of Education of China,2010).This supports the tenet that high quality education embodies facilitating people's comprehensive development in order to match societal development. If higher education could emphasize various methods of development of students' potential and practical skills to realize their theoretical knowledge and satisfy the needs of the human resources market, i.e. graduates with the skills of learning, studying, finding, analyzing and solving problems, and team cooperation, the quality of students entering the workforce would improve as the quality of the classroom teaching catered to their needs.

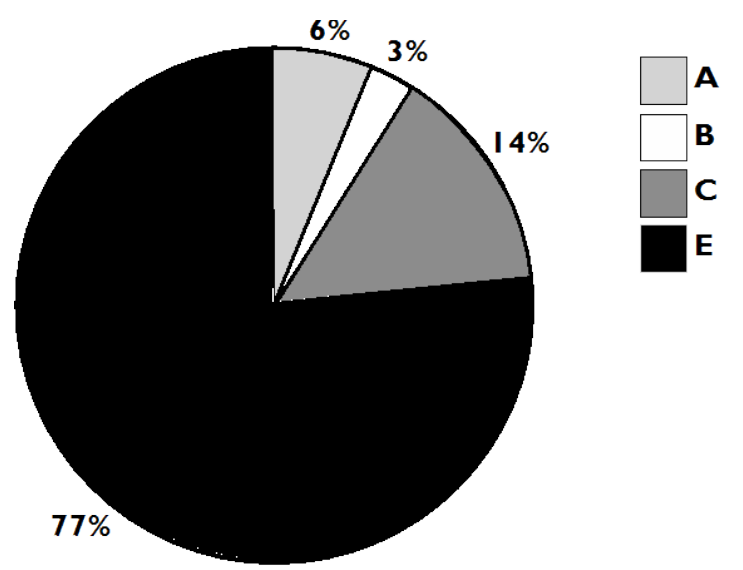

Notes:A. Lecturers talking, students listening; B. Lecturers talking, questioning little, students listening; C. Lecturers talking, questioning more, students listening \&answer little; D. Lecturers talking, continual questioning, requiring students answers, students join in actively; E. Creating a responsive atmosphere, guiding students to join in and sharing knowledge and information. Respondents : 861 Art Undergraduates

Chart 1.

Percentage of learning styles that undergraduates would like to experience.

Table 1.

Rankings of learning styles experienced by undergraduates.

\begin{tabular}{cccccc}
\hline & Options & $\begin{array}{l}\text { A.Lecturers talking, } \\
\text { Students listening }\end{array}$ & $\begin{array}{l}\text { B.Lecturers talking, } \\
\text { questioning little, } \\
\text { Students listening }\end{array}$ & $\begin{array}{l}\text { C.Lecturers talking, ques- } \\
\text { tioning more, Students listen- } \\
\text { ing \& answering a little }\end{array}$ & $\begin{array}{l}\text { D.Lecturers talking, continual } \\
\text { questioning requiring student } \\
\text { answers, Students join in actively }\end{array}$ \\
\hline 1 & $71.8 \%$ & $20.44 \%$ & $7.6 \%$ & 0 \\
2 & $14.9 \%$ & $76.08 \%$ & $9.02 \%$ & 0 \\
3 & $7.6 \%$ & $2.28 \%$ & $82.24 \%$ & 1.2 & $9.88 \%$ \\
4 & $5.48 \%$ & $1.2 \%$ & & $92.12 \%$ \\
\hline
\end{tabular}

Respondents : 861 art undergraduates (Huang, 2013). 
Classroom teaching in universities is a process that assists students to develop and improve their abilities and quality of life. The goal of teaching is to prepare students for their careers and the needs of daily life(Hativa, 2010). It is more important that education develops undergraduates' capabilities of learning, studying, finding, analyzing and solving problems, and teamwork rather than just transforming knowledge. It means wisdom is more important than knowledge and the process of teaching is more important than the result(Yuan, 2007).This experimental research focused on developing the willingness to challenge authority, building up a method of critical thinking, improving the competencies of academic research and creativity, training the skills of finding, analyzing and solving problems and the ability of teamwork by subject knowledge, which is the carrier, and interactive teaching styles, which are an approach.

\section{ResearchMethodology and Samples}

Based on theliterary review, sampling surveys and the discussion on the essence of education, quality of education and the goal of classroom teaching in higher education, we introduced presentationsand interactive teaching styles to several groups of students at Sichuan Normal University.

\section{Methodology}

This research applied a predominately constructivist paradigm combined with a pragmatic paradigm. The researchers and students worked together to create effective teaching and learning. In this research, a sample survey method was used, which questioned the efficiency of the teaching styles before and after completion of constructive research from the experimental and contrast student groups, followed by data and information collection. Observation and filming of the presentation performance and the students' performance in class was conducted. A teacher - student interview was organized, which was unstructured like a conversation, or a discussion (Mertens, 386) to gain more details (Denzen\& Lincoln, 2005). Contrast- ing comparison methods, which compared the changes between the experimental group and contrast group students, and ahistorical comparison, which compared changes before and after the experiment were used.

\section{Research Samples}

The empirical researchsamples were chosen from undergraduates in years two and year three in the Faculty of Education atSichuan Normal University. Each semester, two classes totaling around one hundred students were selected as subject- participants. Firstly the experimental group who were taught using the interactive teaching style and secondly, the contrast group students who were taught using a traditional transmission teaching style.

The researchwasconducted over three semesters involving an experimental group of 158 students and a contrast group of 150 . It was conducted in the Leadership Psychologycourse from March to July 2009, with 61 experimental students and 50 contrast students. The second research was conducted from September 2009 to January 2010, in the OrganizationalBehavior in Education coursewith 51 experimental students and 50 contrast students, followed in September 2010 through to January 2011 in the OrganizationalBehavior in Educationcourse with 46 experimental students and 50 contrast students.

\section{The Research Procedures}

The empiricalresearch introduced several interactive teaching styles that suited the new teaching ideals into the experimental groups, especially Presentation Teaching Methods and group classroom discussion.

\section{The Questionnaires Before the Experiment}

In the second week of the semester, the questionnairesrelating to which abilities had been trained and how much ability had been improved were conducted in the experimental group and contrast group (Table 2).

Table 2.

Degreesof improving between experimental and contrast group students before the experiment.

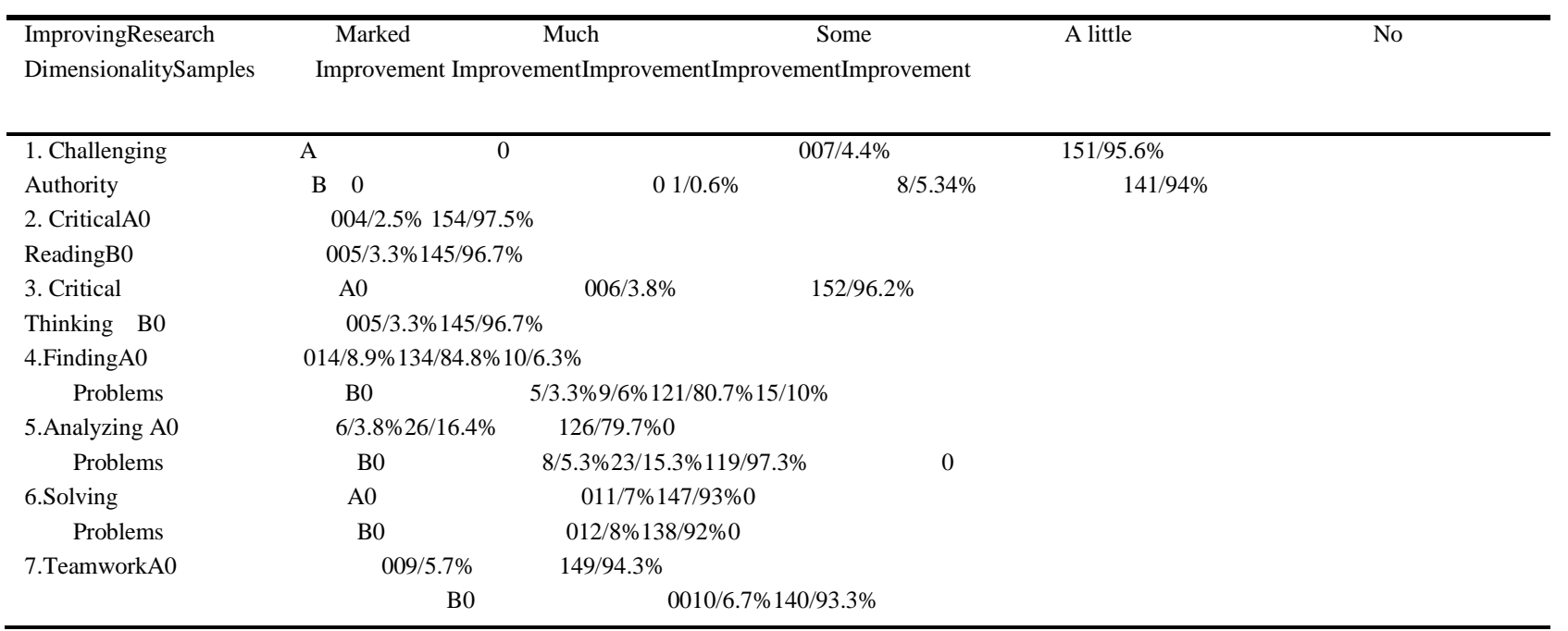

Note: A: 158 Experimental group students' answer (introduced interactive teaching styles) B: 150 Contrast group students' answer (without introduced interactive teaching styles) 
The research found that both the experimental and contrast group, were very weak. $94.8 \%$ of respondents believed they had no improvement in challenging authority, $96.7 \%$ of respondents could not improve their abilities of critical reading and thinking, $87.9 \%$ of respondents had little improvement in the competencies of finding, analyzing and solving problems, and $93.8 \%$ of respondents did not improve their competence of teamwork. No responders showed a marked improvement in any of the above aspects, and only $3.3 \%$ and average $4.55 \%$ of responders had much improvement in finding and analysing problems. This indicated a great weakness in cultivating the capabilities that society needs using the traditional transmission teaching methods. The difference of improvement between the experimental group and contrast group students was very small.

\section{The Process of the Experiment}

We implemented the experimental researchin the course unitsfortwo periods per week that, totaling twenty-six periods each semester.

\section{An Introduction of Educational Philosophy and Teaching Methods}

In the first period, the philosophy, goals, teachers' roles in the classroom and Group Presentation method was introduced to the experimental class students. This included:

\section{Understanding the Philosophy of Classroom Teaching}

Developing students' comprehensive abilities is more important than the transmission of knowledge. Teaching knowledge is a platform for cultivating students' abilities. The purpose of education is to train students various abilities through engaging them to participate in the teaching-learning activities, which are preparing, presenting, answering questions and assessing other students' presentations. The consequence is that they actively explore and discover knowledge.

\section{Understanding the Goal of Classroom Teaching}

- Firstly, help the students to understand why they need to form ahabit of consciouslychallenging academic authority and to improvetheir critical thinking.

- Secondly, how to developcompetencies in academic research, which include learning how to research academic information, how to develop opinions by critical reading and critical thinking.

- Thirdly, training students'to apply theoretical knowledge, which includes: finding issues from society, identifying social problems, analyzing these problems by applying theories and finally finding solutions to those issues.

- Finally, teach the students how to produce PPT presentations, working in groups and practicing teamwork.

\section{Understanding of the Teachers' Role in the Classroom}

As the educator Dewey pointed out, teachers are participants in the learning process. Their task is guiding students to discover the contents of the field independently(Dewey, 1897). Therefore, teachers are suppliers and guiders. They offer various kinds of learning skills and methods, and updatedinformationin the classroom. So, a mailbox was set up for students and teachers sharing information, opinions and articles in the experimental groups.
The Composition of Student Assessment

In order to objectively assess students' comprehensive competencies, the assessment divides into different parts and stages, which include $5 \%$ for attendance, $5 \%$ for classroom debating, $10 \%$ for group classroom discussion, $30 \%$ for group presentation and $50 \%$ for final essay.

\section{Building up the Ability to Consciously Challenge Academic Authority}

From the second period, lecturers started to guide the students in how to point out inadequacies in the textbook or the teacher's explanations, and then encouraged them to share their thoughts with the class. As well as giving topics for discussion in the classroom to be presented by each student in two weeks, students were offered ten study cases to choose from for their group presentation to be presented, beginning in four weeks, one group a week.

\section{Experiment of Group Discussion}

In the third period, lecturers started to guide the studentsto formstudy groups based on their interest in the offered cases and considering factors such as gender and student leaders in order to assure the optimal combination and effectiveness of the teams. Every group had 5-6 students. After selecting a team leader, students sat together with team members and completed the group discussion together in the classroom at all times. The group's score is the individual's score. The procedures are:

- Group members researched individually on the topic they chose before the classroom discussion

- Students discuss for twenty minutes and lecturers observe and listen to them

- Each group chooses one representative to state in five minutes, the key points of the topic and to sum up their opinions

- Lecturer makes a comment to each group statement according to performance of members, academic terms used and the level of theoretical analysis during the discussion

- Lecturer gives the group score immediately.

\section{Experiment on Group Presentation}

The lecturer provides a list of casesrelating to the knowledge of this subject. After each group selects a case, they collect and critically read the relevant information and theories from academic books, journals and online academic papers. Then, to build up their own views and opinions they look for supporting theories, analyzing the practical problems in the case. This is followed by discussion of the case with team members and developing a presentation essay using power point. Finally, all the members of the group will conduct a presentation in the classroom. Group's score is the individual's score.

\section{The Preparation of Group Presentation}

- Choosing topic together from the offered list of cases

- Distributing the task to group members

- Members individually research the basic information about the company in the case study

- Members discussion: contributing the findings, what the problems and issues are, what could be improved and what theories were used to support the solution

- Students form outline of presentation

- Lecturer discusses the outline with student groups and 


\section{P. HUANG ET AL.}

offers suggestions

- Group members work together to improve the contents of presentation essay and produce Power Point presentation.

Group Presenting

- The group presents their PPT to their classmates for thirty minutes, each member speaking no less than four minutes

- Answering questions created by classmates for fifteen minutes

- Group hand in their presentation essay and Power Point production.

Assessment from other Groups and Lecturer

- Other student groups will take ten minutes to assess the group presentation. They evaluate the presentation performance according to the Evaluation Criterion supplied by the lecturers. The students will hand in their assessments immediately after completion.

- Teacher's comments for twenty five minutes include:

a. Individual performance

b. The quality of Power Point c. Clarity of the issues and problems, how accurately the theories match the case, the logicality of analysis and integrityof the presentation.

- Giving suggestions, relevant theories and research methodology

- Encouraging other student groups to develop different opinions.

\section{Questionnaires after Experiment}

In order to ascertain the effectiveness of teaching-learning methods to improve abilities, a comparison questionnaire was conducted in both the experimental group and the contrast group at the end of the semester(see Table 3). The Paired Samples Test for the experimental student group showing the degree of ability improvementwas done before and after the experiment. From Table 4, it can be seen that students in the experimentalgroup presented a remarkable difference $(p<0.001)$ in seven dimensionalities before and after the experiment. This indicated that the students' abilities in these seven aspectsshowed a notable improvement attributable to the training methods.

Table 3.

Degrees of improvement between experimental and contrast groupsafter the experiment.

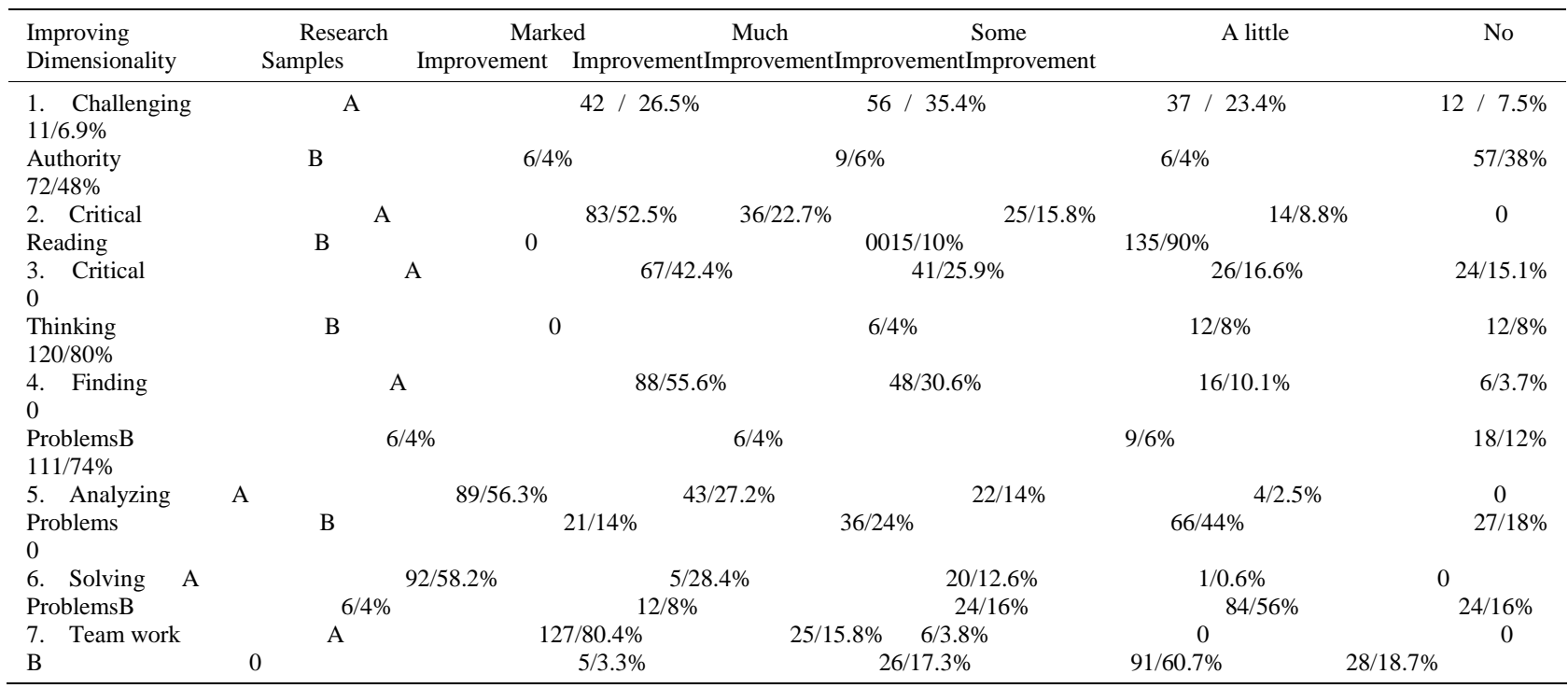

A: 158 Experimental group students' answer (introduced interactive teaching styles). B: 150 Contrast group students' answer (without introduced interactive teaching styles).

Table 4.

T Test for paired sample of experimental groups $(N=158)$.

\begin{tabular}{llcc}
\hline Contents of Improving & M & SD & T \\
\hline 1. Challenging authority & -2.627 & 1.154 & $-28.617^{* * *}$ \\
2. Critical reading & -3.165 & 1.009 & $-39.438^{* * *}$ \\
3. Critical thinking & -2.911 & 1.119 & $-32.690^{* * *}$ \\
4. Finding problems & -2.367 & 0.752 & $-39.583^{* * *}$ \\
5. Analyzing problems & -2.082 & 0.773 & $-33.839^{* * *}$ \\
6. Solving problems & -2.373 & 0.736 & $-40.553^{* * *}$ \\
7. Teamwork & -3.722 & 0.528 & $-88.619^{* * *}$ \\
\hline
\end{tabular}

Note $* * *$ represent for $\mathrm{p}<0.001$ 


\section{Observation of Students’ Performance}

Each experimental group's presentation wasvideoed. The video showed that as the experimentproceeded, the later student groups showed greater improvement in the seven aspects than the prior groups.Contrasting the performance between the first and final group's presentations, the final group's presentation was noticeably better than the first one.

\section{Interview}

Several students were interviewed a year after the experiment was completed. The feedback indicated that students learned many skills from the interactive teaching styles, especially from the group presentation, which they wereable to apply to other subjects and social activities.

\section{Analysis of Experiment Results}

The experiment involved three classes over a period of two years. At the end of the semester, asurveyof the experimental groupstudents indicated that various kinds of competencies, such as summarizing issues, presenting skills, critical reading and thinking,finding, analyzingand solving problems, questioning and debating in the classroom had improved. It also showed thatthese students liked the interactive teaching style. $86.05 \%$ liked small groupdiscussion and $81.40 \%$ likedgrouppresentation. Comparing the results with traditional transmission teaching styles, $91.7 \%$ of experimental groupstudents chose Presentation Teaching Methods as their preferred method of learning.

\section{Historical Comparison}

The improvement in competence between groups before and after implementing the new teaching styles has been substantiatedby questionnaire data.

\section{Improvement in Consciously Challenging Academic Au- thority, Critical Reading and Thinking}

It can be seen (Table 5) that there was an improvement of consciously challenging authority from $95.6 \%$ of students with No Improvement to $26.5 \%$ of studentswith Marked and $35.4 \%$ with Much Improvement, totalling more than 60\%.Similarly, more than $75 \%$ of students in critical reading and more than $68 \%$ of students in critical thinking showedMarked and MuchImprovement.Notably, most of them improved in challenging authority. From the recorded video, it can be found that after the first group presentation, no studentshad questions, but most actively and conscientiously took notes. Gradually, more and more students began to question actively, to debate points with classmates, and seek clarification ofthe lecturer's evaluation ofthe group presentations. As the experiment went by, students questioned and debated more and more vigorously, always within the rules and style of academic debating.

\section{Developmentof the Ability to Find, Analyze and Solve Problems}

Although the survey prior to the experiment showed (Table 5) that ability to find, analyze and solve problems was better than consciously challenging authority, critical reading and thinking, it also showed that $93.7 \%$ of students improved at finding problems.However, 84.4\% have A Little Improvement, and there was no improvement at the Marked and Much levels. In improvement of analyzing problems, only $3.8 \%$ of students improved at theMuchlevel and $79.7 \%$ of students showed $A$ Little Improvement. Similarly in the ability to solve problems, 93\% of students improved A Little. All these data indicated that the students could not improve their ability to find, analyze and solve problems effectively under the traditional teachinglearning methods.

However, it can be seen from The Paired Samples Test (Table 4) that the students had an obvious improvement in their ability to find, analyze and solve problems after implementation of interactive teaching methods, where group presentation was the dominating factor. Moreover, Table $\mathbf{5}$ indicates that the percentage of students who showedMarked Improvement in finding, analyzing and solving problems was 55.6\%, 56.3\% and $58.2 \%$, and the percentage who showedMuch Improvementwas $30.6 \%, 27.2 \%$ and $28.4 \%$. No studentsshowedNo Improvement.

Table 5.

Degrees of improvement between before and after the experiment in the experimentalgroups.

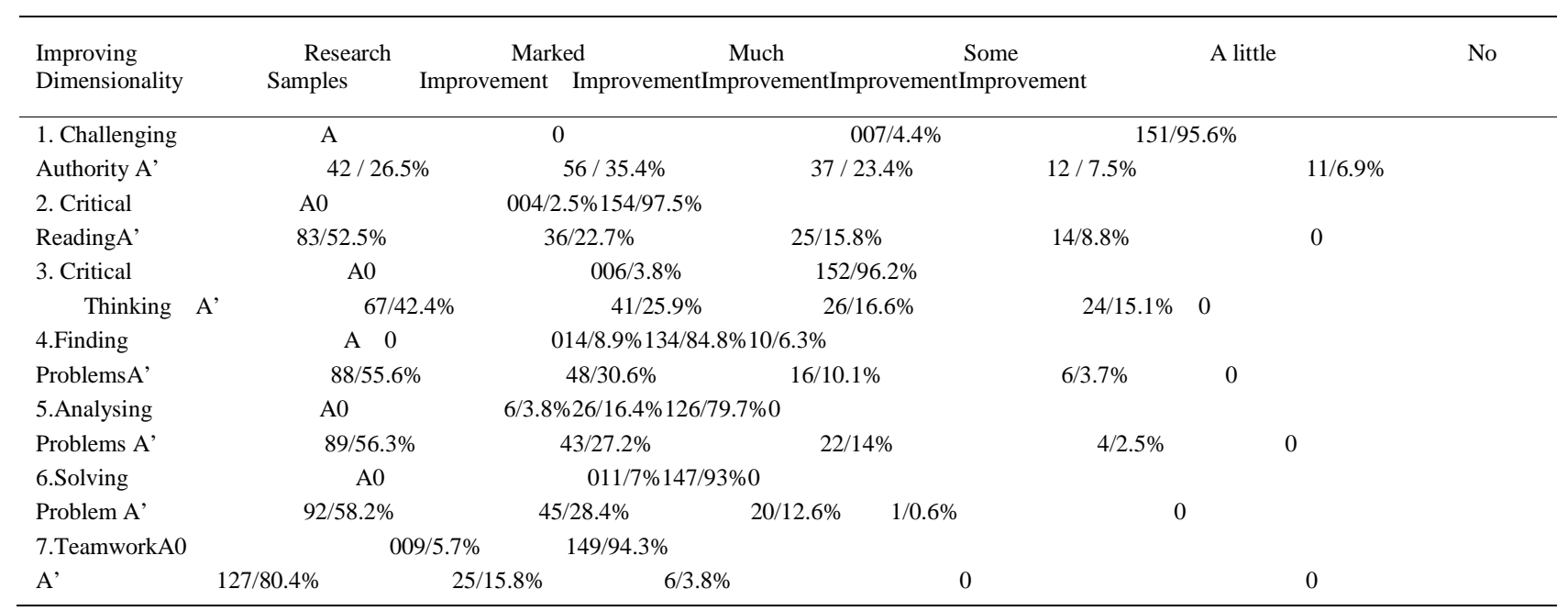

Note: A: 158 Experimental class students' answer before experiment. A': 158 Experimental class students' answer after experiment 
In order to calculate the degree of improvementin the ability to find, analyze and solve problems after the experiments,we chose the case study essays from the first two Group's Presentations. We then collected the students' individual final essays, which werestill in the case study style,at the end of experiment, and compared them with their group presentation essays.We found that $93.3 \%$ of students were able to solve $90 \%$ of the problems presented in the case study, $76.7 \%$ of students were able to analyze the problems theoretically and present solutions, followed by $13.3 \%$ who recommendeda reasonable solution.

After the experiment, most students were able to systematically analyze the case study by using logic and theories related to the course units,forming their own opinions and solutions. They were also able to respond to questions and participate in debates withclassmates.

\section{A Marked Improvement in Teamwork}

Before the experiment, the questionnairesshowed that $94.3 \%$ of students showed No Improvement and 5.7\% showedLittle Improvement in teamwork. However, after the experiment, the percentage of students who showedMarked, Much and Some improvement were $80.4 \%, 15.8 \%$ and $3.8 \%$, which means $100 \%$ of students had varying degrees of improvement. These improvementswerealso confirmed by conducting a detailed interview. Most students realized the importance of communication and cooperation when working in a group. Moreover, they realized they should communicate and cooperate with group members althoughthey may have time restraints imposed by a busy university study regime and sometimes,marked differencesin personal opinions and attitudes. They learned how to respect each other's opinions and achieve a common view through academic arguments. They said, “ It waspainfulbut happy during the experimental procedure”. Not only the ability to cooperate has been learned from it but also some valuable teamwork skills.

\section{Contrasting Comparison}

As discussed above, before the experiment the difference between the experimental groups and contrast groupswas very small. Under the traditional teaching-learning methods presently being practiced, the abilities which today's society requires, of finding, analyzing and solving problems are anun- dervalued and mostly ineffective area of the curriculum. Both students' ability to consciously challenge authority and the academic competencies of critical reading and thinking appear are weak.

After the experiment, the surveyover three semesters showed that there was a marked difference between contrast groups and experimentalgroups on seven dimensions (Table 3), which includeconsciously challenging authority, critical reading and thinking, finding, analyzing and solving problems, as well asteamwork. The percentages of improvement in the experimental groups are much higher than in the contrast groups. Firstly, $61.9 \%$ of experimentalgroupstudents achievedMarked and MuchimprovementinChallenging authority, comparedwith 10\% in the contrast groups.On the aspects of critical reading and thinking, experimental students improved 52.5\% inMarked degree and $42.4 \%$ in Much degree, while the contrast students showed no improvement in these two aspects in Much degree. Moreover, if we considerMarked and Much improvement, more than $83 \%$ of the experimental groups' students showed improvement inproducingsolutions and finding and analysing problems, compared with the contrast group with 38\% improvement foranalyzingproblems, followed by $12 \%$ for producingsolutions and $8 \%$ forfinding problems. In addition, the difference in teamwork becomes very obvious, where $80.4 \%$ of the experimental students improved Marked compared with zero in the contrast students.

The Chi-squareTest shows the number of improved students in both theexperimental and contrast groups (Table 3-4).The outcomes clearly indicateanobvious difference $(\mathrm{p}<0.01)$; that in the seven dimensions observed, the students in the experimentalgroupsshowed greater improvement than those in the contrast groups.

\section{Other Outcomes}

\section{Contribution to Social Activities}

The students in the experimental groups in 2009 achieved high results in the university-run competition of Excellent Class, for utilizing the skills they acquired during the process of researching and compiling information for their group presentation. They believe this is because their ability to comprehend and professionally present their findings had been cultivated by the interactive teaching-learning methods.

Table 6.

Difference of the degree of improvementbetween experimental and contrast groups after the experiment $\left(\chi^{2}\right)$.

$\chi^{2}(\mathrm{df}=4)$

$\begin{array}{ll}\text { 1. Challenging authority } & 157.41^{* *} \\ \text { 2.Critical reading } & 279.01^{* *} \\ \text { 3.Critical thinking } & 222.16^{* *} \\ \text { 4.Finding problems } & 223.10^{* *} \\ \text { 5.Analyzing problems } & 81.57^{* *} \\ \text { 6.Solvingproblems } & 199.91^{* *} \\ \text { 7.Team work } & 271.81^{* *}\end{array}$

P.S : **represent for $\mathrm{p}<0.01$. 


\section{Skills Learned}

The experimental group students took part in peer-group assessment, allotting grades to classmates. From this they learned how to evaluate each other's work and gained a deeper understanding of the requirements of group presentation, enabling them to enhance the quality of their performance in the classroom. Moreover, the students could now confidently respond to questions from and debates with classmates using theories and knowledge gained through the presentation teaching-learning methods. Students also acquired the skill of making a Power Point production.

\section{Appropriate Amount of Presentations}

The presentation teaching-learning methods received positive feedback, but that does not mean that students should necessarily be taught using this method alone. Results of interviews with students in Lingnan College of Zhongshan University, suggested that, although they like the method, they would prefer it for no more than four subjects each semester. This is because the presentations will consume more of their time and energy than traditional teaching methods, time which is not available for those who have more than five courses in one semester in Chinese universities.

\section{Conclusion}

It has been stated that undergraduates could gain higher quality learning through interactive teaching-learning methods. These include transferring course and subject knowledge as a carrier, conducting presentations and discussions, creating an environment where students are engaged, encouraging undergraduates to participate in class activities, and finally, creating positive interaction between lecturers and students and allowing students to take an active part in their learning.

Moreover, every student in the experimental groups completed at least five evaluations of other group presentations and a series of questioning and debating sessions with classmates, as well as their own presentation and peer assessment. These repeated experiences reinforced and improved the students' ability to produce a clear and concise presentation. Through this experience, their ability to consciously challenge authority and read and think critically, had been gradually improving. It also gave incentive to students to enhance their abilities of academic researching and writing, creating and innovation. In addition, the experimental group students' expertise in finding, analyzing and solving problems by applying academic theories was predominant. Through this method, the efficiency of classroom teaching could increase and improved quality would be ensured. In this way, the undergraduates not only learn the knowledge, but also the methods of practical application of that knowledge, through this, the requirements of the human resources market are being trained and cultivated. The newly developed abilities would provide a strong basis for undergraduates' daily life and career in thefuture.
However, it is desirable to have a comfortable balance between both teaching methods, and lecturers are best placed to assess when, and with which classes interactive teaching is appropriate. The extra workload imposed on students and lecturers and the sudden increase in PPT or similar presentations needs to be considered.Both methods can be employed concurrently and flexibly to maintain a positive and continual improvement in the overall education of students.

\section{REFERENCES}

The Ministry of Education Press Office \&China National Institute for Educational Research. (2010).

Dialogue to Educational Hot Topics in 2009(pp)113, Beijing, Educational Science Publishing House.

Department of Education, Training and Youth Affair (2000). The Australian Higher Education Quality Assurance Framework, Occasional Paper Series, Canberra. www.detya.gov.au/highered/mceetya-cop.htm

Dewey, J. (1897). My Pedagogic Creed. Retrieved from http://book. Google.com/books

http://en.wikipedia.org/wiki/John_Dewey P9

Hativa,N.(2010).Teaching for Effective Learning in HigherEducation(pp38).Dordrecht: Kluwer Academic Publishers press Hang Ping. (2009). A Discussion ofTheQuality Assurance in Higher Education in Australiaand the inspiration to China, Journal of SouthwestUniversity for Nationalities (Humanities and Social Science), 220, 273-278.

Huang Ping. (2013). Reflecting onthe Research Methodology Based onThe research of Improving the Effectiveness of Classroom Teachingof Higher Education in China. In the proceedings of Economics and Social Science (pp.200-206), Information Engineering Research Institute,USA

Jia Fuming. (2007). Educational Essence-What is Real Education (pp7). Beijing, World Publishing Corporation.

Li Shuqin\& Li Lingli. (2011). On theTheory and Strategy of Effective Teachingin Colleges and Universities in the New Period. HeilongjiangEducation(Higher Education Research \& Appraisal), 939, 20-22.

Ma yaqing\& Liu Lengxing. (2008). Quality andAccountability inHigher Education(pp.9-10).Beijing, BeijingNormal University Publishing House.

Mertens, D. M. (2005). Research and Evaluation in Education andPsychology: Integrating diversity with Quantitative, Qualitative, and Mixed Methods (pp.2 \& 88-189).Thousand Oaks, London, Sage press.

Ministry ofEducation of China. (2010). Essentials of National Middle-Long-term Educational Reform and Development Plan （20102020)(pp.9).Beijing, BeijingNormal University Publishing House.

Song Qiuqian. (2011). On thePractical Strategies of Effective Teaching in Colleges and Universities.Research in Educational Development, No.5, 74-75.

Yi Qizhi. (2010). On the Effectiveness of Classroom Teaching in Universities. Journal of Guangxi Teachers Education University (Philosophy and Social Sciences Edition), 31, 108-110.

Yuan Zhenguo.(2007). New Ideain Education(pp.14). Beijing, Educational Science Publishing House.

Zhao Jushan\&GuoJunying. (2010). On theMethod of Enhancing Effective Teaching of teacher. China Higher Education, 13, 14, 28-30. 